\title{
AUTOMATIC COUNTING OF SPERMATOZOA IN RABBIT SEMEN
}

\author{
J. E. KILHSTRÖM AND D. FJELLSTRÖM \\ Institute of Zoophysiology, University of Uppsala, Sweden
}

(Received 16th March 1967)

Electronic methods have been used for automatic counting of spermatozoa in semen from bulls (Glover \& Phipps, 1962; Iversen, 1964), guinea-pigs (Laurence \& Carpuk, 1963) and man (Segal \& Laurence, 1962). The main obstacle to automatic counting of rabbit spermatozoa is the high degree of contamination of rabbit semen with granular particles, many of them being of the same size as the spermatozoa. In addition, some semen specimens contain a gelatinous substance which is sometimes difficult to remove completely by mechanical treatment. In spite of these difficulties Fowler \& Hellman (1965) have obtained fairly good results in counting rabbit spermatozoa automatically. However, their method does not permit the discrimination between spermatozoa and other particles of about the same volume. The present communication gives the results obtained using an electronic cell counter for counting rabbit spermatozoa after the irrelevant particles had been eliminated.

Semen was obtained from eight sexually mature rabbits of the Bourgogne Breed by means of an artificial vagina. All specimens were treated and diluted within $1 \mathrm{hr}$ and counted within $4 \mathrm{hr}$ after ejaculation. Immediately after the collection of semen the gelatinous substance, if present, was removed with a glass spatula. In most cases it was possible to remove the gel substance completely in this way; any droplets which might have remained, would be dissolved during the treatment which follows. By means of a capillary pipette $0.1 \mathrm{ml}$ of semen was transferred to a test tube equipped with a ground-glass stopper, followed by $2.0 \mathrm{ml}$ of a $5 \%$ solution of Glasol (commercial name for a synthetic washing-material, manufactured by Åtvidabergs Industrier Ltd, Sweden, and containing $15 \%$ anionic, synthetic wetting medium, $5 \%$ fatty acid amide, $0.5 \%$ bactericidal substance and $0.05 \%$ perfume, $\mathrm{pH} 7 \cdot 1$ ). To the well mixed contents were added $3.0 \mathrm{ml}$ of a dust-free $0.9 \%$ solution of sodium chloride (Fyskosal, Pharmacia Ltd, Sweden) and after thorough mixing the suspension was used for counting in a haemacytometer. A sample containing $0.1 \mathrm{ml}$ of the suspension was further diluted with Fyskosal to $100 \mathrm{ml}$ and the dilute suspension was used for the electronic counting.

Manual microscopic triplicate counts were performed using a Buerker haemacytometer. In all but seven ejaculates at least $3 \times 400$ cells were counted. In five of the remaining seven ejaculates, all characterized by a low sperm concentration, the number of counted spermatozoa was at least $3 \times 200$. The remaining 
two ejaculates were practically free from spermatozoa. Sperm concentrations were estimated for correlation analysis in fifty-nine first ejaculates and eighteen second ejaculates using microscopic as well as electronic counting.

Electronic counting was performed with the aid of a Celloscope 202 automatic particle counter (Öhlin, 1958) manufactured by Lars Ljungberg \& Co. Ltd, Sweden. The sample tube had a capillary aperture of $100 \mu$ and the instrument was calibrated by means of standard latex particles with a mean diameter of $2 \cdot 85 \mu$. Five electronic readings per sample were recorded and averaged. Each reading lasted $39 \mathrm{sec}$. During this time $1 \mathrm{ml}$ of the suspension

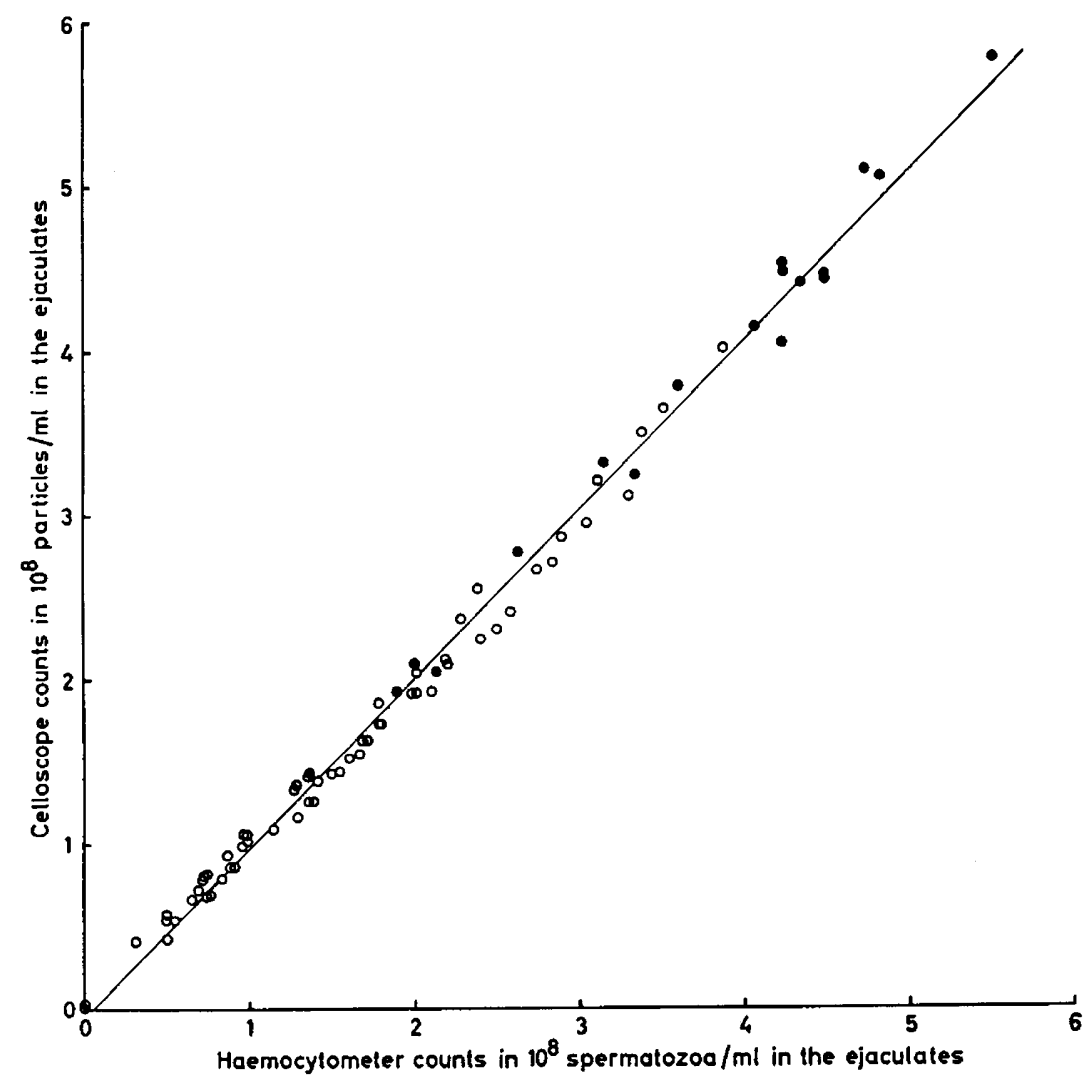

Text-Fig. 1. Celloscope counts obtained from fifty-nine first ejaculates $(0)$ and eighteen second ejaculates $(\bullet)$ plotted against the corresponding haemacytometer counts.

passed through the aperture and, at most, 10,000 particles were counted. Measurements were performed with the attenuator set at $1 / 1$, the current intensity control at 5.90 , and the two discriminators at 10 and 93 , respectively. With this adjustment the two recorders registered all particles with a volume bigger than 7.23 and $65.41 \mu^{3}$, respectively. The difference between the figures obtained gives the number of particles within this range of size, which corresponds to spherical particles with diameters from $2 \cdot 4$ to $5 \cdot 0 \mu$.

Microscopical observations have shown that treatment of rabbit semen with 
the commercial washing material, Glasol, completely removes the particulate contaminations as well as the gel substance leaving, however, the spermatozoa apparently intact though immotile. With the use of $5 \%$ solution of Glasol and the quantities stated above, this effect persisted even when the suspension had been diluted to a sperm concentration suitable for electronic counting. In all ejaculates tested, the total number of particles counted within the range of size given above coincided closely to the number of sperm cells counted in the haemacytometer. In Text-fig. 1 the Celloscope counts $(y)$ are plotted against the corresponding haemacytometer counts $(x)$. The equation of the regression line is $y=-0.0362+1.0238 x$ and the correlation coefficient 0.996 . As can be seen from Text-fig. 1 the values obtained from the examination of the first and second ejaculates cluster around the same regression line. The mean value of all Celloscope counts was $2.074 \times 10^{8}$, and of all haemacytometer counts 2.061 $\times 10^{8}$.

Our results clearly demonstrate the suitability of electronic methods for rapid counting of rabbit spermatozoa. The most obvious disadvantage of electronic counting methods, namely, the lack of discrimination between relevant and irrelevant particulate matter is greatly reduced by the treatment outlined above; the difference between haemacytometer and Celloscope counts thus becomes very small. Nevertheless, the comparatively high Celloscope counts found in two ejaculates which were practically free from spermatozoa (Text-fig. 1), indicate the presence of a small amount of particulate matter, such as epithelial cells, dust particules and bacteria, with a volume close to that of the spermatozoa.

This work has been supported by a grant from the Swedish Natural Science Research Council.

\section{REFERENCES}

Fowler A. K. \& Heliman A. (1965) An electronic method for counting and sizing rabbit spermatozoa. Fert. Steril. 16, 778.

Glover, F. A. \& Phipps, L. W. (1962) Preliminary study of an electronic method of counting and sizing bull spermatozoa. 7. Reprod. Fert. 4, 189.

IVERSEN, S. (1964) Evaluation of the number of spermatozoa in bull semen. A comparison between electronic counting, light scattering and absorptiometry. F. agric. Sci. 62, 219.

Laurence, K. A. \& Carpuk, O. (1963) The counting and sizing of guinea pig spermatozoa. Fert. Steril. 14, 451 .

Öhlin, E. (1958) Automatisk cellräkningsmetod-speciellt för blodkroppar. Nord. Med. 59, 577.

Segat, S. J. \& Laurence, K. A. (1962) Automatic analysis of particulate matter in human ejaculates. Ann. N. Y. Acad. Sci. 99, 271. 